0

doi: 10.5004/dwt.2019.24277

\title{
Catalytic ozonation of nitroimidazole antibiotics using nano-magnesium hydroxide as heavy-metals free catalyst
}

\author{
Qi Sun, Guangcan $\mathrm{Zhu}^{\mathrm{a}, *}$, Jun $\mathrm{Wu}^{\mathrm{b}, *}$, Jian $\mathrm{Lu}^{\mathrm{c}}$, Zhenhua Zhang ${ }^{\mathrm{b}}$ \\ aSchool of Energy and Environment, Southeast University, Nanjing, Jiangsu 210096, China, email: gc-zhu@seu.edu.cn (G. Zhu) \\ ${ }^{b}$ School of Resources and Environmental Engineering, Ludong University, Yantai, Shandong 264025, China, \\ email: wujunlisa@163.com (J.Wu) \\ ${ }^{\circ}$ CAS Key Laboratory of Coastal Environmental Processes and Ecological Remediation, Yantai Institute of Coastal Zone Research \\ (YIC), Chinese Academy of Sciences (CAS); Shandong Key Laboratory of Coastal Environmental Processes, YICCAS, \\ Yantai Shandong 264003, China
}

Received 13 January 2018; Accepted 13 April 2019

\section{A B S T R A C T}

In this study, nano-magnesium hydroxide (nano- $\mathrm{Mg}(\mathrm{OH})_{2}$ ) was prepared and first applied for the catalytic ozonation of the widely used nitroimidazole antibiotics. Most of nitroimidazole antibiotics were rapidly removed within $10 \mathrm{~min}$. The removal rate constant of metronidazole in the catalytic ozonation treatment was four times higher than that without catalyst. Persistent high catalytic activity of nano- $\mathrm{Mg}(\mathrm{OH})_{2}$ maintained after three runs. The severe inhibition of hydroxyl radical scavenger (TBA) on the catalytic ozonation suggested that hydroxyl radical reaction served as the predominant process. The removal of nitroimidazole antibiotics followed a pseudo-first order kinetic model. Increase in the dosage of catalyst and reaction temperature within certain range could enhance the degradation of metronidazole, tinidazole, and dimetridazole while increase in the initial concentration of nitroimidazole antibiotics led to the decrease in the removal efficiency. All anions $\left(\mathrm{Cl}^{-}, \mathrm{HCO}_{3}^{-}\right.$, and $\left.\mathrm{SO}_{4}^{2-}\right)$ and cations $\left(\mathrm{Ca}^{2+}\right.$ and $\left.\mathrm{Mg}^{2+}\right)$ had negative influence on the removal efficiency of nitroimidazole antibiotics. Due to the unique features such as low cost and heavy-metals free, high efficiency and persistent high catalytic activity of the nano- $\mathrm{Mg}(\mathrm{OH})_{2}$ in the catalytic ozonation of nitroimidazole antibiotics demonstrated that nano- $\mathrm{Mg}(\mathrm{OH})_{2}$ is a promising environment-friendly ozonation catalyst in terms of antibiotic removal.

Keywords: Nano-scale magnesium hydroxide; Nitroimidazole antibiotics; Catalytic ozonation; Degradation

\footnotetext{
${ }^{*}$ Corresponding authors.
} 